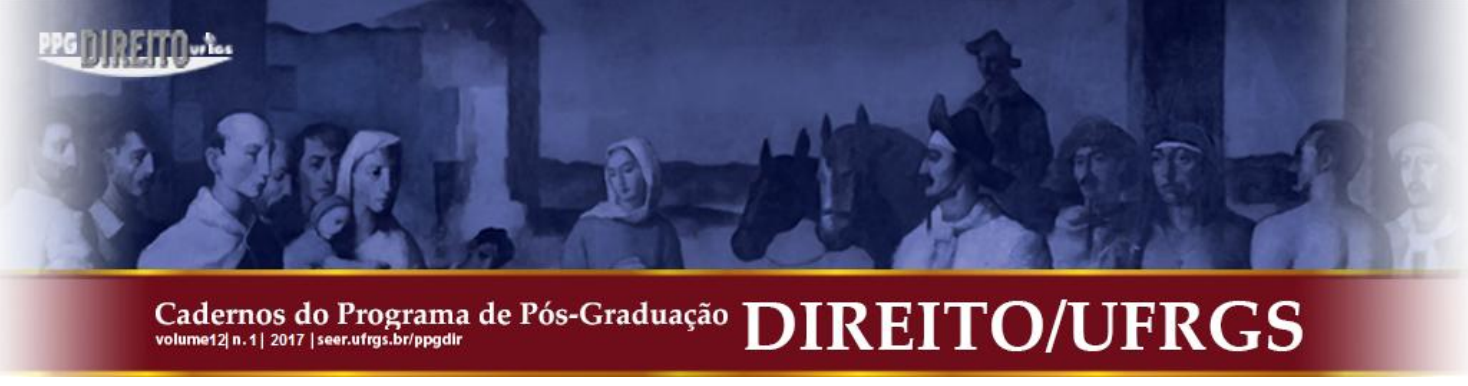

\title{
SISTEMA PENAL FUNCIONALISTA E O DIREITO PENAL DO INIMIGO
}

\author{
FUNCTIONALIST PENAL SYSTEM AND ENEMY CRIMINAL LAW
}

\author{
Ricardo Bispo Razaboni Junior* \\ Rafael José Nadim de Lazari***
}

\begin{abstract}
RESUMO: O presente trabalho objetiva tecer considerações acerca do funcionalismo penal e do direito penal do inimigo. Para isso, faz referência às escolas penais e às teorias do delito, adentrando, posteriormente ao estudo do funcionalismo teleológico-racional e ao funcionalismo sistêmico-radical. Adiante, faz considerações acerca das velocidades do direito penal, objetivando expor o direito penal do inimigo e seus fundamentos. O método empregado é o dedutivo, pois procura resgatar as principais justificativas das teorias que fundamentaram o pensamento funcionalista e do direito penal do inimigo, obtendo como problemática a possível aplicação das referidas teorias. Deste modo, conclui-se que a teoria oferecida por Claus Roxin aparenta ser a mais aceitável no plano jurídico atual, sendo dispensada, consequentemente, o funcionalismo de Günther Jakobs e totalmente pugnada sua teoria do inimigo.
\end{abstract}

PALAVRAS-CHAVE: Escolas Penais. Teorias do Delito. Funcionalismo. Velocidades do Direito Penal. Direito Penal do Inimigo.
ABSTRACT: The present work aims to make considerations about the criminal function and criminal law of the enemy. To this end, it refers to criminal schools and theories of crime, going further to the study of rational-teleological functionalism and systemic-radical functionalism. He then makes considerations about the speeds of criminal law, aiming to expose the criminal law of the enemy and its foundations. The method used is the deductive, since it seeks to recover the main justifications of theories that founded the functionalist thinking and the criminal law of the enemy, obtaining as problematic the possible application of these theories. In this way, it is concluded that the theory offered by Claus Roxin seems to be the most acceptable in the current juridical plane, being consequently dispensed with the functionalism of Günther Jakobs and totally challenged his theory of the enemy.

KEYWORDS: Criminal Schools. Tort Theories. Functionalism. Speeds of Criminal Law. Enemy Criminal Law.

SUMÁRIO: Introdução. $1 \mathrm{O}$ início das Escolas Penais. 2 Causalismo, Neokantismo e Finalismo- Teorias do Delito. 3 O sistema Funcionalista Teleológico-Racional. 4 O sistema Funcionalista Radical ou Sistêmico. 5 O Direito Penal do Inimigo de Jakobs. Considerações Finais. Referências.

\section{INTRODUÇÃO}

O Funcionalismo Penal e o Direito Penal do Inimigo são teorias que ganham a cada dia relevância no cenário mundial, devido ao fato de serem propostas e estudadas por grandes doutrinadores nacionais e internacionais.

O objetivo deste trabalho é analisar a dogmática destas teorias, fazendo a reconstrução histórica dos fundamentos que levaram a criação destas, apresentando-as posteriormente, para ao final concluir qual teoria funcionalista seria a melhor aplicável e se o Direito penal do inimigo e seus fundamentos se mostram aceitáveis atualmente. Para isso, o método

\footnotetext{
* Mestrando em Teoria do Direito e do Estado pelo Centro Universitário Eurípedes Soares da Rocha, São Paulo.

** Pós-Doutor em Democracia e Direitos Humanos pelo Centro de Direitos Humanos da Faculdade de Direito da Universidade de Coimbra, Portugal. Doutor em Direito Constitucional pela Pontifícia Universidade Católica de São Paulo (PUC-SP). Professor do curso de Mestrado em Direito do Centro Universitário Eurípedes Soares da Rocha, São Paulo.
} 


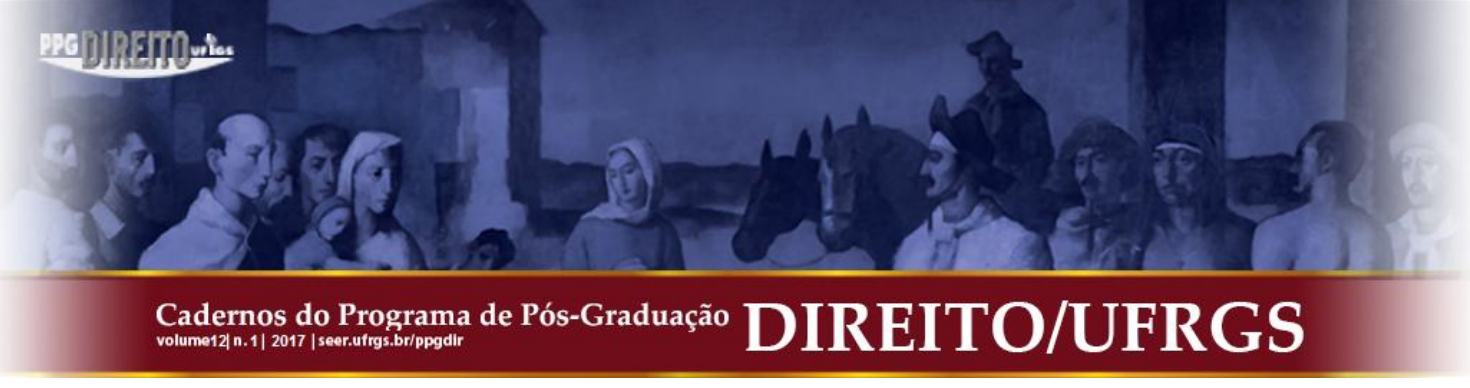

empregado é o dedutivo. Utilizam-se pesquisas bibliográficas como principal fonte de observação histórica e teórica.

Deste modo, em síntese, a pesquisa trata, inicialmente, do início das escolas penais, fazendo referência ao surgimento da Escola Clássica e a Escola Positivista.

Em capítulo seguinte, abordar-se-á os sistemas cognominados como: Causalismo, Neokantismo e Finalista, os quais se mostrarão essenciais para o entendimento dos sistemas funcionalistas.

Adentrando ao apogeu, será discorrido o Funcionalismo Penal Teleológico-Racional, criado pelo alemão Claus Roxin em meados de 1980, sendo posteriormente exposto o Funcionalismo Sistemico-Radical, originado pelo também jurista alemão Günther Jakobs.

Por fim, serão analisadas as velocidades do direito penal, criadas pelo doutrinador espanhol Silva Sanchez, com foco, em especial, na terceira velocidade do direito penal, o chamado Direito Penal do Inimigo, criado também por Jakobs, o qual se mostra como uma teoria fundada no funcionalista sistêmico-radical e na racionalidade comunicativa.

Justifica-se que o presente estudo não tem como intuito esgotar o tema, mas sim trazer informações que instiguem o debate, a fim de colaborar para futuras pesquisas dedutivas e hipotético-dedutivas acerca da temática.

\section{O INÍCIO DAS ESCOLAS PENAIS}

Primeiramente, analisar-se-á a origem das escolas penais, cognominação presenteada por Flávio Augusto Monteiro de Barros para as escolas provindas do pensamento jurídicofilosófico acerca da etiologia do delito e dos fundamentos e objetivos do sistema penal (MORAES, 2011, p. 109).

Num contexto histórico penal, percebe-se que as escolas penais marcaram os períodos humanitários (“o homem deve conhecer a Justiça”) e cientifico (“o Direito deve conhecer o homem”), no que se refere à matéria criminal. Tais ideologias transformaram e influenciaram a evolução da dogmática penal, tanto na perspectiva da teoria do delito, quanto nas concepções acerca das finalidades das penas (MORAES, 2011, p. 110).

Nesse sentido, em meados do século XVIII, Cesare Beccaria, baseado nos princípios do contrato social do direito natural e do utilitarismo, trazidos por Montesquieu, Hume e Rousseau, se mostrou como um ícone da personificação do movimento humanitário, o qual 


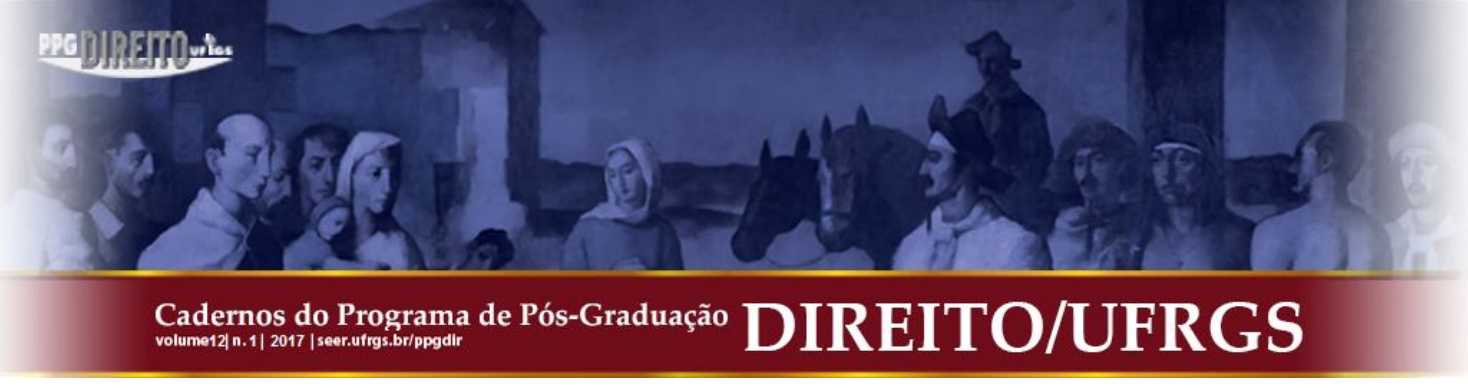

lutou contra penas cruéis, torturas, dentre outras incoerentes incriminações e desigualdades que eram determinadas de acordo com a classe social do malfeitor (MORAES, 2011, p. 110).

Surge, desde então, a Escola Jurídica Italiana, denominada posteriormente por Enrico Ferri de Escola Clássica Criminal. Tal movimento originou outros percussores, como Carrara, Romagnosi (Genesi Del Diritto Penale) e Rossi (Tratatto di Diritto Penale).

A fim de compreender a definição de escola clássica, tem-se que é útil analisar a delineação do delito que Carrara apresentou e que centraliza os "postulados capitais" dessa escola. Neste plano, ensina-se que delito é a infração da lei estatal proclamada para escudar a segurança social, resultante de um ato externo do homem, sendo este positivo ou negativo, moralmente imputável e politicamente danoso. (GARCIA, 1976, p. 86).

Passando a análise do período científico, esse que se pauta na necessidade do Direito conhecer o homem, deu-se lugar à ideia de Lombroso, Garofalo e Ferri, a qual fora chamada de Escola Positiva. No âmbito político-social, a Escola Positiva afirmou a necessidade de se restabelecer o equilíbrio entre os direitos dos indivíduos e os do Estado. (MORAES, 2011, p. 112).

(...) se a Idade Média tinha visto somente o delinqüente e a Escola Clássica tão somente o homem, a realidade impunha ter em conta o homem delinqüente, não desconhecendo no delinqüente os direitos insuprimíveis do homem, mas não esquecendo nunca a insuprimível necessidade da defesa social contra o delinquiente (FERRI, 1999, p. 64-65).

Conforme pautado por Ferri, a dessemelhança da Escola Clássica e da Positiva está pautada no método hipotético-dedutivo e na lógica abstrata, já que a primeira tem como objeto o crime, como entidade jurídica, e esta tem como objeto o delinqüente como pessoa, revelando-se mais ou menos socialmente perigoso pelo delito praticado (FERRI, 1999, p. 64).

\section{CAUSALISMO, NEOKANTISMO E FINALISMO- TEORIAS DO DELITO}

Neste tópico, abordar-se-á as principais teorias do delito. Primeiramente, analisar-se-á a teoria causal da ação, ou causal-naturalista, a qual fora desenvolvida por Franz Von Liszt e Ernst Von Beling.

A teoria pressupõe que ação é a transfiguração do mundo externo causado pelo líbito humano, isto é, causação cuja resultância se deu por um ato de vontade, compreendido como gesto corpóreo voluntario, com “tensão (contradição) dos músculos”, determinada, não por 


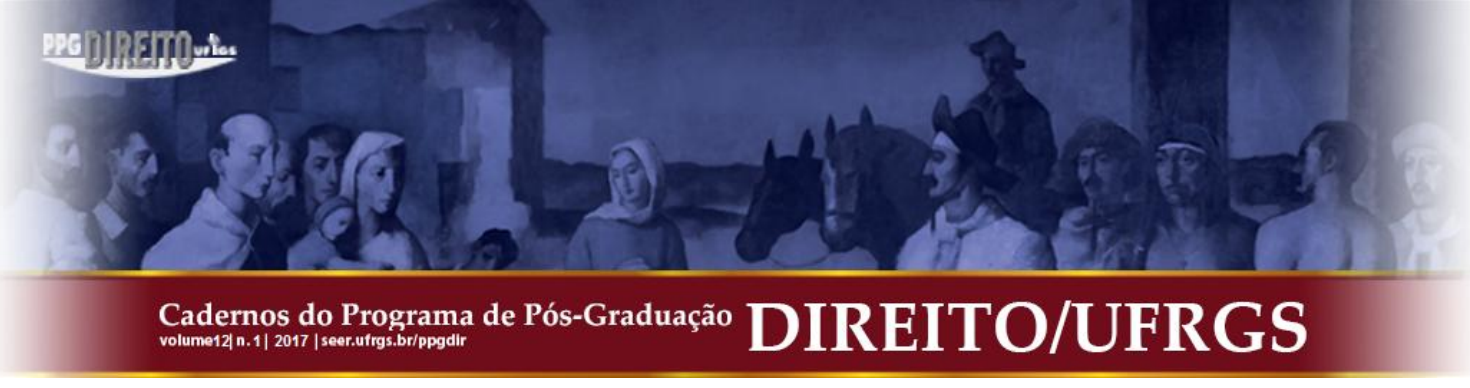

imposição, mas por convicções ou representações e executadas pela intervenção dos nervos. (MORAES, 2011, p. 119).

A influência do positivismo penal sobre a teoria causal foi responsável por uma concepção de ciência que somente poderia ser apreendida através dos sentidos, sobre aquilo que seria mensurável (FONSECA, 2009, p. 159).

O sistema compreende de modo diverso a afirmação de que o tipo penal abrange os elementos objetivos e descritivos; a antijuricidade, o que houver de objetivo e normativo; e a culpabilidade, o subjetivo e descritivo (MORAES, 2011, p. 119). Nasce assim a definição de que o tipo compreende uma descrição objetiva de uma modificação do mundo exterior. A antijuricidade se define formalmente, como oposição à ação típica de uma norma do direito, a qual se fundamenta na ausência de causas de justificação. A culpabilidade, por sua vez, é psicologisticamente conceituada como a conexão psíquica entre o agente e o fato (GRECO, 2000, p. 2).

Por fim, condensa Claus Roxin que o sistema 'clássico' do delito de Von Liszt e Beling, o qual foi predominante no início do século e que na atualidade permanece bastante influente, cujas categorias perduram na atual dogmática alemã, principiava da conjectura de que injusto e culpabilidade se conectavam um ao outro como o lado externo e interno do delito. (ROXIN, 2002, p. 198-199).

No que se refere ao Neokantismo, tem-se que este nasceu da superação do paradigma positivista-naturalista, o qual adotou dois entendimentos essenciais.

O primeiro se fez por meio da Escola de Marburgo, por seu principal representante Stammler, o qual se mostrava de limitada reflexão nas Ciências Penais. Em segundo plano, tem-se a Escola Sul-ocidental, formada por Lask, Radruch e Sauer.

Diferenciando-as, observa-se que a Escola de Maburgo, por meio de ensinamentos de Stammler, expôs o alicerce formal da ciência jurídica, enquanto a Escola Sul-ocidental, por meio de seus pensadores, procurava conceder conteúdo valorativo às estruturas formais. (MIR PUIG, 1976, p. 232 e ss.).

Ainda neste sentido, resgata-se o pensamento de Radruch, o qual expõe que:

(...) a teoria do "delito justo" de Stammler é só um método que não desenvolve nenhum sistema de Filosofia de Direito (...). Adquire a validade geral de seus conceitos em virtude de seu caráter puramente formal. Assim, é menos uma filosofia jurídica que uma lógica da consideração valorativa do Direito, uma crítica da razão 
jurídica; certos cimentos de utilidade pouco comum para toda filosofia do Direito, mas ainda não o edifício mesmo (...) (1976, p. 236).

Seguindo adiante, Stammler, adotando o conhecimento de Kant (daqui se originou o termo Neokantismo) distingue a "matéria" da "forma", bem como observa a distinção entre as ciências "causais", ou "naturais", das ciências "finais" (GOMES, 2007, p. 135).

As ciências "causais" ou "naturais" são demonstradas pela independência da Ciência do Direito em relação à ciência natural, independência esta fundada na ciência dogmática do Direito que não investiga as "causas", mas os "finns", em sentido de uma preposição jurídica ou de uma instituição. Em que pese às ciências "finais", considerada por Larenz como mais importante, cabe ao Direito ordenar e classificar conforme um critério superior, o qual torna possível nesta ideia a superação do positivismo jurídico. (LARENZ, 1966, p. 100).

Como forma de sucessão aos ideais do Neokantismo, surge à teoria finalista, a qual em síntese procura vencer o dualismo metodológico do neokantismo, declinando-se a premissa sobre o qual este se firma, ou seja, sob o fato de que entre ser e dever ser existe um abismo impossível de se ultrapassar. A realidade, para a corrente finalista, já apresenta em si um mandamento interno, possui uma coerência intrínseca: "a lógica da coisa (Sachlogik). Neste plano, o direito não pode "flutuar nas nuvens do dever ser, vez que o que vai regular é a realidade". (GRECO, 2000, p. 5).

Apesar de ambos serem respostas ao movimento que lhe antecediam, o Neokantismo fora resposta à restrita interpretação da realidade levada fielmente pelo positivismo e o naturalismo. Por sua vez, o finalismo, inclinava-se pela ontologia, pelo "ser", demonstrandose como resposta ao ponto de vista considerado unilateral do Neokantismo (GOMES, 2007, p. 139).

Depreende-se então que o "ser" só age finalisticamente; logo se o direito quer proibir ações, só pode proibir ações finalistas (GRECO, 2000, p. 5).

Nesta esteira, logicamente o finalismo segue estruturas lógicas-reais, tornando-se explicável que, esta teoria, que fora criada por Hans Welzel, e também é chamada de teoria final da ação, refere-se, em síntese, que a conduta humana é o exercício de uma finalidade e, por isso, a ação é um acontecer final, e não, apenas causal. 


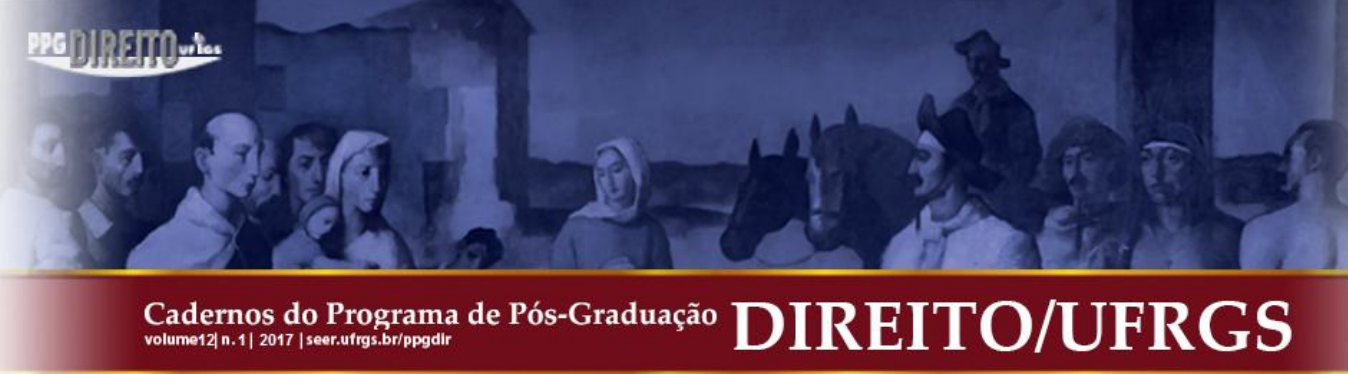

Assim explica Claus Roxin:

(...) a chamada teoria finalista, que dominou a discussão dogmática penal das primeiras duas décadas do pós-guerra, chega, por sua vez, a um novo sistema do Direito Penal. Seu ponto de partida é um conceito de ação diverso das antigas concepções sistemáticas, consideravelmente mais rico de conteúdo. Para ela, a 'essência' da ação que determina a totalidade de estrutura do sistema, encontra-se no fato de que o homem através de uma antecipação mental, controla cursos causais e seleciona meios correspondentes no sentido de determinado objetivo, 'supradeterminando-o finalisticamente' (ROXIN, 2002, p. 200).

Em crítica à teoria finalista, Hassemer apresenta que apesar de esta não ter estimulado o nazismo ou ampliado o coro das escolas anti-liberais da era nazista, resta axiomático que o entendimento pessoal de ação e de antijuricidade, como se retira dos ensinamentos penais finalísticos, encontravam um correspondente contemporâneo, mesmo que desvirtuado, no 'Direito Penal da vontade', elaborado pelo pensamento penal nazista (HASSEMER, 1993, p. 20-21).

\section{O SISTEMA FUNCIONALISTA TELEOLÓGICO-RACIONAL}

Ao analisar o Funcionalismo Teleológico-Racional, observa-se, em primeiro plano, que a estrutura dessa dogmática penal reside na teoria do consenso de Habermas e na teoria sistêmica de Luhmann, ambas estabelecidas nas ideias de Merton e Parsons.

Assim, nota-se que no âmbito penal há três linhas básicas funcionalistas. A primeira, criada por Claus Roxin, se faz por meio do funcionalismo moderado, o qual é voltado para a necessidade de que a Política Criminal possa penetrar na dogmática penal (MORAES, 2011, p. 127).

No mesmo plano, expõe o funcionalismo limitado, o qual se justifica por sua utilidade social, mas se vincula ao Estado Social e Democrático de Direito, com todos os seus limites exclusiva proteção de bens jurídicos, princípio da legalidade, intervenção mínima, culpabilidade, dignidade e proporcionalidade, proposto por Mir Puig (MORAES, 2011, p. 127).

Por fim, denota o funcionalismo radical ou sistêmico, oferecido por Günther Jakobs, o qual é representado pelo funcionalismo sociológico inspirado na Teoria dos Sistemas de Luhmann (MORAES, 2011, p. 127). 


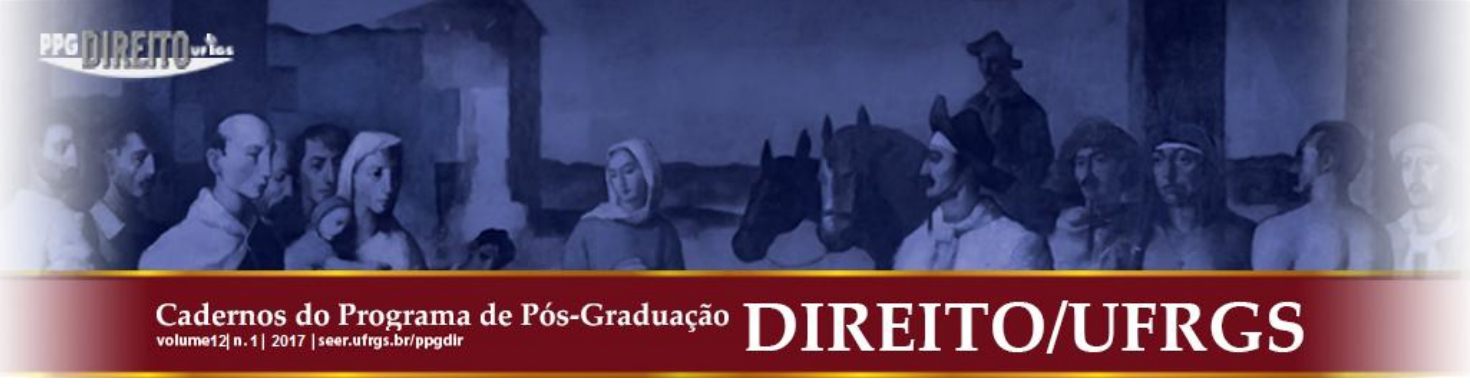

Porém, elucidamos que há outras correntes funcionalistas, como, in verbis, o funcionalismo do controle social, ofertado por HASSEMER (1998, p. 37), o qual se ampara no garantismo penal de Luigi Ferrajoli e propõe um "novo ramo" do direito, cognominado como direito de intervenção, e o funcionalismo reducionista ou contencionista, ofertado por Zaffaroni, o qual procura reestruturar os elementos do crime, com foco principal na tipicidade. (ZAFFARONI; ALAGIA; SLOKAR, 2001).

Adiante, seguindo os ideais do funcionalismo estrutural de Parsons, o qual é identificado no Direito Penal como teleológico, valorativo e 'moderado', surge o sistema funcionalista moderado ou teleológico-racional, que fora concebido pelo jurista alemão Claus Roxin, considerado um dos mais influentes dogmáticos do direito penal germânico.

Desde meados de 1970, de acordo com ROXIN (2002, p. 205), tem sido desenvolvido um sistema "jurídico penal teleológico-racional ou funcional", o qual busca superar, de modo definitivo, o modelo científico-natural ou lógico causal por um conjunto de normas orientadas a uma valoração jurídica. (PORTUGAL, 2013, p. 12).

Apesar de existirem diversas teorias funcionalistas, podemos observar que os defensores deste movimento estão de acordo - apesar das muitas diferenças quanto ao resto em que a construção do sistema jurídico penal não deve vincular-se a dados ontológicos (ação, causalidade, estruturas lógico-reais, entre outros), mas sim orientar-se exclusivamente pelos fins do direito penal (GRECO, 2000, p. 7).

A princípio, Roxin destaca que o funcionalismo, a rigor, encontra-se inserido em uma conjuntura metodológica ampla, a chamada jurisprudência de valores. Nesse sentido:

\footnotetext{
(...) esta pode ser entendida como o método segundo o qual as construções jurídicas devem ser conscientemente guiadas por determinados valores e finalidades. Toda jurisprudência dos valores tem, portanto, uma questão fundamental a resolver: de onde se retiram os valores sobre os quais se edificará o sistema? (ROXIN, 2002, p. 62-63).
}

Roxin destaca ainda que desde 1970 encontra-se "empenhando esforços bastante discutidos no sentido de desenvolver um sistema jurídico co-penal 'teleológico-racional' ou 'funcional"” (ROXIN, 2002, p. 205).

Trata-se de um método firmado pelo cuidado pragmático, o qual é considerado como resposta à demasiada abstração do finalismo, sui generis, ao seu ontologismo, tencionando 


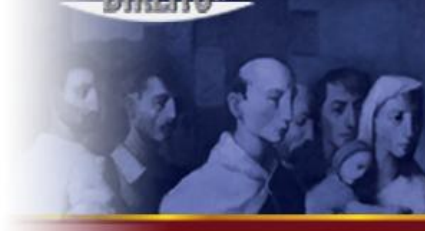

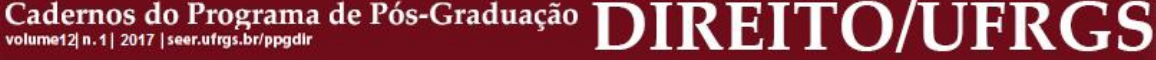

guiar a dogmática penal por meio das funções político-criminais exercidas pelo Direito Penal, modificando-a funcional ou funcionalizando-a.

Nessa esteira, Luís GRECO (2000, p. 7) manifesta a conjectura da patente dessemelhança entre o finalismo e o funcionalismo, se referindo primeiramente ao finalismo como sendo a fixação de dolo eventual e sua delimitação da culpa consciente. Welzel soluciona o dilema por meio de considerações meramente ontológicas, não questionando a valoração jurídico-penal. Assim, a finalidade se faz pela vontade de realização, compreendendo não só o que o autor efetivamente deseja, como, in verbis, as consequências que sabe necessárias e as que considera possíveis e que assume o risco de gerar. Deste modo, concluí que o valor pré-jurídico não é modificado pela valoração jurídica; a finalidade se mantém finalidade, ainda que passe a ser cognominada de dolo.

Em outra conjuntura, no que se refere ao funcionalismo, observa que não interessa, prima facie, até que ponto a estruturação lógico-real da finalidade pode alcançar, visto que ainda que algo exista e seja univocamente cognoscível, a problemática que se tem à frente é um "problema jurídico, normativo, a saber: o de quando se mostra necessária e legítima a pena por crime doloso?”. Neste plano, o funcionalismo entende que, quando mais exigir para o dolo, mais acrescenta na liberdade dos cidadãos, à custa da proteção de bens jurídicos, e consequentemente, quanto menos exigências formular para que haja o dolo, mais terá a proteção de bens jurídicos e mais limitará a liberdade dos cidadãos. (GRECO, 2000, p. 8).

Conclui Greco, expondo que são diversas as concepções possíveis da realidade, coroando que:

\footnotetext{
O finalista pensa que a realidade é unívoca (primeiro engano), e que basta conhecêla para resolver os problemas jurídicos (segundo engano-falácia naturalista); o funcionalista admite serem várias as interpretações possíveis da realidade, de modo que o problema jurídico só pode ser resolvido através de considerações axiológicas, isto é, que digam respeito à eficácia e à legitimidade da atuação do direito penal. (GRECO, 2000, p. 8).
}

Numa análise da teoria de Claus Roxin, esta se apresenta como uma síntese entre o pensamento dedutivo (valorações político-criminais) e indutivo (composição de grupos de casos). Defende-se assim, que o Direito Penal somente deve atuar nos casos em que o bem jurídico venha a ser violado, de modo que se não for, deverá ocorrer a incidência do princípio da insignificância como forma de excludente material de tipicidade. (GRECO, 2000, p. 9). 


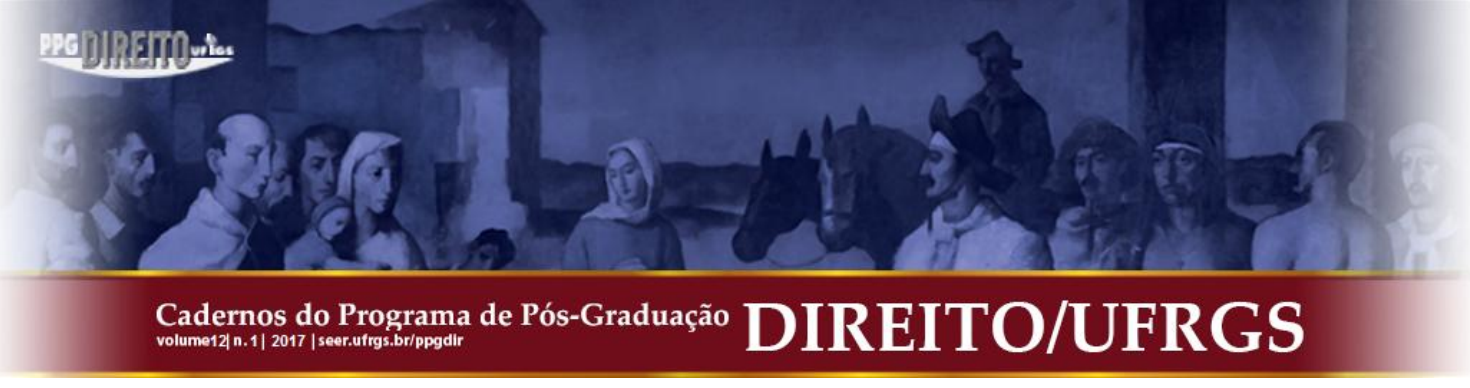

Ademais, defende ainda que mesmo o fato sendo típico, ilícito e culpável, há outras formas mais eficazes e oportunas do que a sanção penal.

Deste modo, conclui-se que o finalismo se mostra como uma doutrina ontologista, que prejulga o problema de um modo valorativo, já o funcionalismo de Roxin se trata de uma doutrina teleológica, orientada para realização de certos valores provindos de Política criminal acolhida pelo Estado social de direito, a fim de assegurar os bens jurídicos tidos como indispensáveis para a sociedade.

\section{O SISTEMA FUNCIONALISTA RADICAL OU SISTÊMICO}

Tendo como seu principal opositor Claus Roxin, o jurista alemão Günther Jakobs cria, em meados de 1980, a teoria funcionalista sistêmica ou radical, provocando polêmicas e gerando debates que se estendem até o presente momento.

Jakobs, baseando-se principalmente nas ideias de Niklas Luhmann (NIKITENKO, 2006, p.127), e ao contrário de Roxin, instiga uma nova fundamentação da dogmática jurídico-penal e do sistema, atrelando a missão do Direito penal (prevenção geral) com a perspectiva sociológica-funcionalista (GOMES, 2007, p. 147).

As divergências significativas, por sua vez, separam os pontos de vistas do funcionalismo moderado do radical, e superam a esfera metodológica. Neste sentido, JesusMaria Silva SANCHEZ (1992, p. 70) ensina que de um lado Jakobs, por meio de seu funcionalismo radical, absolutiza o critério funcional, rejeitando toda limitação que descenda do horizonte ontológico, ou até mesmo do sentido ordinário do vocábulo. Em outro prisma, divergem as referências funcionais que, em cada situação, dão conteúdo e significado a cada uma das categorias do sistema.

Em contraposição, o referido autor aduz que o funcionalismo moderado, de Claus Roxin, não confere, por sua vez, tanta magnitude ao sistema penal, muito menos as exigências derivadas dele, conservando certa operatividade dos limites externos ancorados na "esfera do ser (natureza das coisas) ou na própria linguagem”. O funcionalismo de Roxin instrui as categorias do Direito penal às destinações da Política criminal, ou seja, enquanto Jakobs preceitua como decisivas as necessidades "sistêmicas" orientadas à "função do Direito penal", sendo esta a manutenção, prevenção e integração por meio do reforço da norma, Claus Roxin 


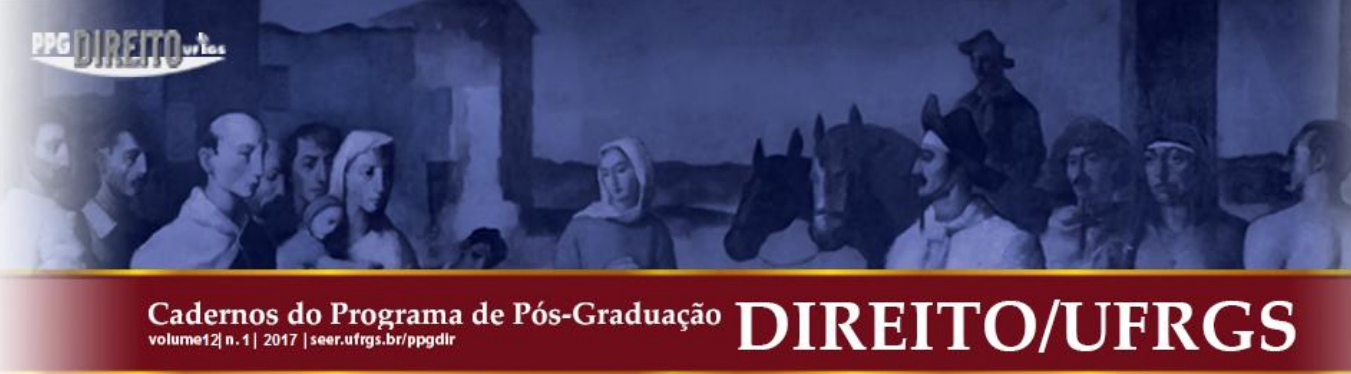

oferece acolhimento a valores e princípios garantistas ao configurar o sistema da dogmática jurídico-penal e do Direito penal. (SILVA SANCHEZ, 1992, p. 70).

A transgressão de uma regra social, ou seja, o delito, é visto de modo socialmente disfuncional, não porque está ferindo ou porque esta colocando em perigo bens jurídicos, mas sim porque questiona a "confiança institucional” no sistema (GOMES, 2007, p. 148).

A delinquência se mostra para Jakobs, primeiramente, como "expressão simbólica de uma falta de fidelidade ao Direito", resultando em constrangimento à plenitude e solidez social. Desta feita, a teoria sistêmica não se confina a resguardar bens jurídicos, pois sim a função. Visa, em plenitude, a confiança institucional no sistema e seu bom funcionamento (GOMES, 2007, p. 148).

Ademais, a doutrina do direito penal como proteção de bens jurídicos, como proposta por Roxin, tampouco apresenta contribuição alguma na limitação da antecipação da punibilidade. Por sua vez, a doutrina do direito penal como proteção da vigência da norma, como proposta por Jakobs, demonstra sua validade especialmente na teoria dos fins da pena: o fato é uma lesão da vigência da norma, a pena é a sua eliminação (JAKOBS, 2005, p. 51).

Neste sentido, revela Jakobs que "o funcionalismo jurídico-penal se concebe como aquela teoria segundo a qual o Direito Penal está orientado a garantir a identidade normativa, a garantir a constituição da sociedade" (JAKOBS, 2003, p. 1).

Jakobs parte do axioma que a função da pena é (re)afirmar a validade da norma em benefício da estabilização do sistema social, considerando por sua vez que a culpabilidade constitui "uma falta de fidelidade ao direito", fundamentando assim a necessidade de pena (MORAES, 2011, p. 134).

Neste momento vale resgatar a teoria clássica do delito e a da ação, a qual Jimenez afirma que, em relação à manutenção da estrutura social:

Todas las categorías del delito en atención a la contribución que éstas prestan en orden al mantenimiento de la respectiva estructura social. En este contexto, El autor rechaza, como es lógico, tanto el método del naturalismo científico de la teoría clásica del delito como el modelo ontológico de la doctrina final de la acción (JIMENEZ, 2006, p. 24).

Jakobs, por outro lado, adotou um novo conceito de ação, o qual dispõe:

(...) La acción, por tanto, es expresión de un sentido. Esa expresión de sentido consiste en la causación individualmente evitable, esto es, dolosa o individualmente imprudente, de determinadas consecuencias; son individualmente evitables aquellas 


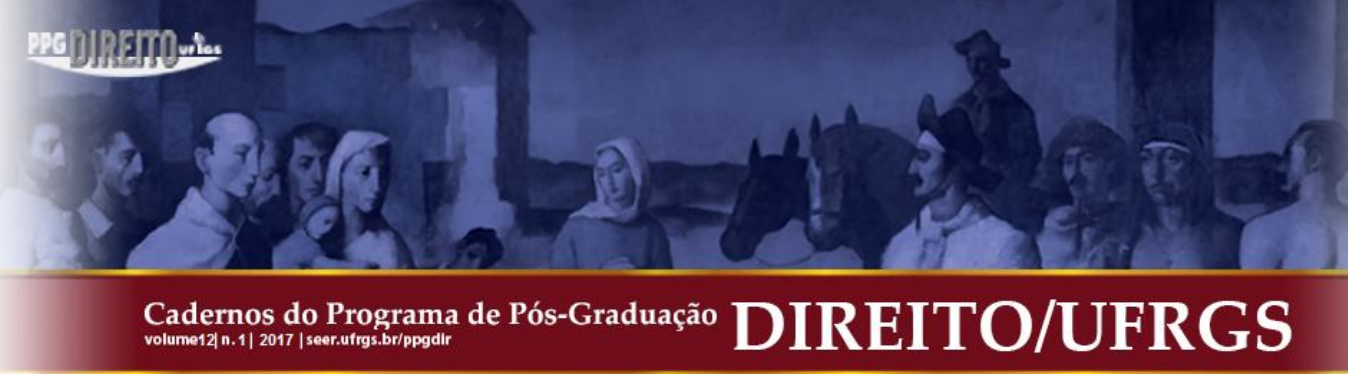

causaciones que no se producirían si concurriese una motivación dirigida a evitar las consecuencias (JAKOBS, 1992, p. 14).

Do mesmo modo, não se pode deixar de validar a oposição ofertada por Claus ROXIN (2002, p. 130), que expõe em primeiro plano sua impressão positiva pela teoria da imputação de Jakobs por sua sólida fundamentação filosófico-sociológica, referindo-se ainda que a beleza do sistema criado por Jakobs não se encontra somente na sua teoria da imputação objetiva, mas também nos reflexos que esta provoca no restante da teoria do crime, bem como na precisão e harmonia com que cada problema é solucionado, sempre devendo levar em conta os efeitos colaterais.

Revela ainda que a concepção do sistema de Jakobs consiste na estruturação da dogmática jurídico-penal com base nos conceitos e categorias provindas da teoria de sistemas sociais, observando-se com enfoque as lições de Luhmann. No que se refere ao conteúdo, controversa peculiaridade da teoria de Jakobs encontra em deixar a culpabilidade ser absorvida pelo conceito de prevenção geral, em concordância com sua teoria dos fins da pena. Assim, a culpabilidade não é algo oferecido ou "objetivamente dado, mas simplesmente 'adscrito' ao autor sem qualquer consideração às suas capacidades concretas na medida daquilo que seja necessário para o "exercício de fidelidade ao direito"” (ROXIN, 2002, p. 130).

Alto se revela o nível da teoria de Jakobs, pois, apesar de ser um opositor tal como Roxin, Batista, por sua vez, também elogia a doutrina, aduzindo que se trata de "uma elaboração teórica de altíssimo nível” dizendo ainda que "poderá fazer sucesso nos países centrais, ricos, com baixa conflitividade social" (BATISTA, 2004, p. 20).

Assim, concluí-se que o funcionalismo de Jakobs procura, sobretudo, assegurar o império da norma, diferentemente de Roxin, que procura instituir valores político-criminais e proteger bens jurídicos.

Ressalta-se, por fim, que o estudo até aqui se mostra essencial para entender os próximos, ou seja, as velocidades do Direito Penal e o Direito penal do Inimigo, já que se encontram inteiramente ligados.

\section{O DIREITO PENAL DO INIMIGO DE JAKOBS}

A fim de recapitular o estudo até aqui, como acentuado por Moraes, tem-se que: 


\begin{abstract}
Nos últimos anos, a concepção clássica do delito (Carrara), a concepção neoclássica do delito (neokantismo) e o sistema finalista do delito (WELZEL), passaram a dialogar com a escola funcionalista dividida basicamente entre as seguintes orientações: o funcionalismo estrutural de Parson (no Direito Penal identificado como teleológico, valorativo e 'moderado' adotado por Roxin) e o funcionalismo sistêmico de Luhmann (no Direito Penal identificado como estratégico, normativista e 'radical', adotado por Jakobs) (MORAES, 2011, p. 124).
\end{abstract}

Para uma assimilação apropriada do Direito Penal do Inimigo e o que este representa ao funcionalismo sistêmico-radical de Jakobs, é necessário esclarecer que, o Direito Penal persiste e obtém o encargo de estabilizar as relações sociais.

Adentrando nas chamadas Velocidades do Direito Penal, estas, revelam-se importantíssimas para o presente estudo, já que se referem ao tempo em que o Estado leva para punir o autor de uma infração penal, sendo esta mais ou menos grave.

Os institutos denominados como Velocidades do Direito Penal foram criadas pelo espanhol Jesús-María Silva Sánchez, o qual é considerado um dos mais respeitados penalistas da atualidade. A teoria traz consigo a ideia de que temos no ordenamento jurídico várias dimensões de Direito Penal, graduados de acordo com sua rigidez (MELIÁ, 2012, p. 92).

Primeiramente, Silva Sanchez divide o Direito Penal em duas velocidades, denominadas como a primeira velocidade e a segunda velocidade, mas por fim, afirma existir uma terceira velocidade, que seria denominada como Direito Penal do Inimigo.

No que se refere à análise dos institutos denominados como velocidades do Direito Penal, Silva Sanchez introduz a primeira velocidade como um modelo de Direito Penal liberal-clássico, garantista, tradicional e mínimo, que se vale preferencialmente da pena privativa de liberdade, como finalidade de uma ação penal, mas se funda em garantias individuais inarredáveis, como meio eficaz para obtenção de justiça, sistema esse adotado pelo Ordenamento Jurídico Brasileiro (SANCHEZ, 2002, p. 40).

No segundo ponto de sua lição, tem-se a análise do Direito Penal de segunda velocidade, instituto que defende a flexibilização, de forma proporcional, de garantias penais e processuais penais, porém fundamentada na certeza da adoção de medidas alternativas à prisão, ou seja, flexibiliza-se garantias devido ao fato de que não haverá a aplicação de pena privativa de liberdade, mas sim penas alternativas, como restritivas de direito e pecuniárias.

Segundo Alexandre Rocha de Almeida de Moraes, as velocidades alusivas acima são verificadas de forma que: 


\begin{abstract}
A primeira, pautado no modelo liberal-clássico, traduz a ideia de um Direito Penal da prisão por excelência, com manutenção rígida dos princípios políticos-criminais iluministas; a segunda, contempla a flexibilização proporcional de algumas garantias penais e processuais, conjugada com a adoção de penas não privativas de liberdadepecuniárias ou restritivas de direitos (MORAES, 2011, p. 230).
\end{abstract}

Como última dimensão do âmbito penalista, tem-se a terceira velocidade, a qual seria, portanto, uma velocidade híbrida, heteróclita, ou seja, com a finalidade de aplicar penas privativas de liberdade (primeira velocidade), com uma minimização ou supressão das garantias necessárias a esse fim (segunda velocidade).

No âmago da terceira velocidade do direito penal encontra-se, portanto, o Direito Penal do Inimigo, ofertado por Jakobs em meados de 1985, e que vem ganhando adeptos e relevância no mundo jurídico, principalmente no hemisfério norte do planeta, após a ocorrência de vários crimes que chocaram a humanidade, como por exemplo, o atentado terrorista de 11 de setembro ao World Trade Center, os atentados terroristas em Madrid e Londres, ocorridos respectivamente em 11 de Março de 2004 e 07 de Julho de 2005 e por fim o atentado a cidade de Paris em 13 de novembro de 2015.

A teoria, originada no pensamento funcionalista sistêmico fundado na racionalidade comunicativa, traz consigo uma distinção entre duas espécies de criminosos: a) os criminosos que têm suas garantias legais preservadas devido ao fato de terem praticados crimes de baixo grau ofensivo, assegurando a esses a preservação do status de cidadão e garantindo, após o cumprimento da penalidade, a manutenção de seus direitos e de sua perspectiva de reintegração social (Direito Penal do Cidadão); b) os criminosos de alta periculosidade que cometeram ou possivelmente poderão cometer crimes de elevado teor ofensivo, e por conta disso sofreriam medidas de segurança próprias, ou seja, penas rígidas a fim de controlá-los, mesmo que de forma antecipada, suprimindo para isto garantias legais e processuais. (Direito Penal do Inimigo).

Em outras palavras:

(...) de acordo com a tese de Jakobs, o Estado pode proceder de dois modos contra os delinqüentes: pode vê-los como pessoas que delinqüem ou como indivíduos que apresentam perigo para o próprio Estado. Dois, portanto, seriam os Direitos Penais: um é o do cidadão, que deve ser respeitado e contar com todas as garantias penais e processuais; para ele vale na integralidade o devido processo legal; o outro é o Direito Penal do inimigo. Este deve ser tratado como fonte de perigo e, portanto, como meio para intimidar outras pessoas. O Direito Penal do cidadão é um Direito Penal de todos; o Direito Penal do inimigo é contra aqueles que atentam 
permanentemente contra o Estado: é coação física, até chegar à guerra. Cidadão é quem, mesmo depois do crime, oferece garantias de que se conduzirá como pessoa que atua com fidelidade ao Direito. Inimigo é quem não oferece essa garantia (GOMES, 2010, p. 2).

Jakobs pondera que são considerados como inimigos do Estado os criminosos econômicos, terroristas, delinquentes organizados, autores de delitos sexuais e outra infrações penais perigosas (JAKOBS, 2003, p. 39). Nesse sentido, conceitua ainda que quem, por princípio, age de modo controverso a norma, não oferece garantia de seu comportamento pessoal. Visto isso, não poderá ser tratado como cidadão, devendo ser combatido como inimigo. Expõe, por fim, que nesta "guerra' há lugar somente para um 'legítimo direito dos cidadãos, em seu direito à segurança; mas diferentemente da pena, não é Direito também a respeito daquele que é apenado, ao contrário, o inimigo deve ser excluído". (JAKOBS, 2005, p. 49-50).

No que diz a respeito à vigência das normas, onde mora grande semelhança com o funcionalismo sistêmico, pontua-se a diferença entre sua finalidade para os cidadãos e para os inimigos, observando que "O Direito Penal do Cidadão mantém a vigência da Norma, o Direito Penal do Inimigo (em sentido amplo: incluindo o Direito das medidas de segurança) combate perigos" (JAKOBS, 2012, p. 29). Em outras palavras, "O Direito penal do cidadão é direito de todos; o Direito penal do inimigo é daqueles que o constituem contra o inimigo: frente ao inimigo, é só coação física, até chegar à guerra”. (JAKOBS, 2005, p. 30).

Tido como um dos principais discípulos do filósofo e jurista do direito germânico, Hans Welzel, Jakobs sustenta sua teoria em diversos fundamentos de filósofos do ius naturale (Direito Natural), como:

a) Rousseau: O inimigo, ao infringir o contrato social, deixa de ser membro do Estado, está em guerra contra ele; logo, deve morrer como tal ; b) Fichte: quem abandona o contrato do cidadão perde todos os seus direitos ; c) Hobbes: em casos de alta traição contra o Estado, o criminoso não deve ser castigado como súdito, senão como inimigo; d) Kant: quem ameaça constantemente a sociedade e o Estado, quem não aceita o "estado comunitário-legal", deve ser tratado como inimigo (GOMES, 2004).

Deste modo, em síntese, pode-se observar que no Direito Natural, há a argumentação a partir de um ponto de vista absolutamente relacionado com a teoria do contrato, onde todo deliquente é um inimigo, como preconizado por Rosseau e Fichte. Entretanto, para a preservação de um destinatário para expectativas normativas, é mais adequado proporcionar o 


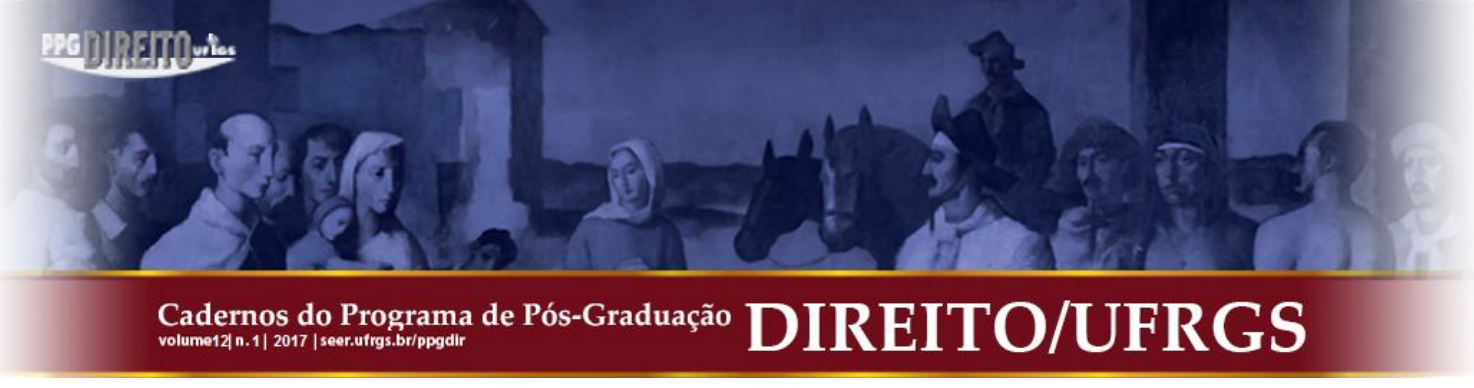

status de cidadãos aos que não se desviam por princípio da norma, como proposto por Hobbes e Kant (JAKOBS, 2009, p. 22).

Por fim, cabe ressaltar que Direito Penal do Inimigo traz consigo três pilares, os quais constituem fundamentos essenciais a sua aplicação e demonstram o porquê de ser conhecida como a terceira velocidade do direito penal, quais são: a) antecipação da punição; b) desproporcionalidade das penas e criação de leis severas direcionadas aos "Inimigos do Estado"; c) relativização e/ou supressão de garantias processuais.

Neste plano, Manuel Cancio Meliá, afirma que:

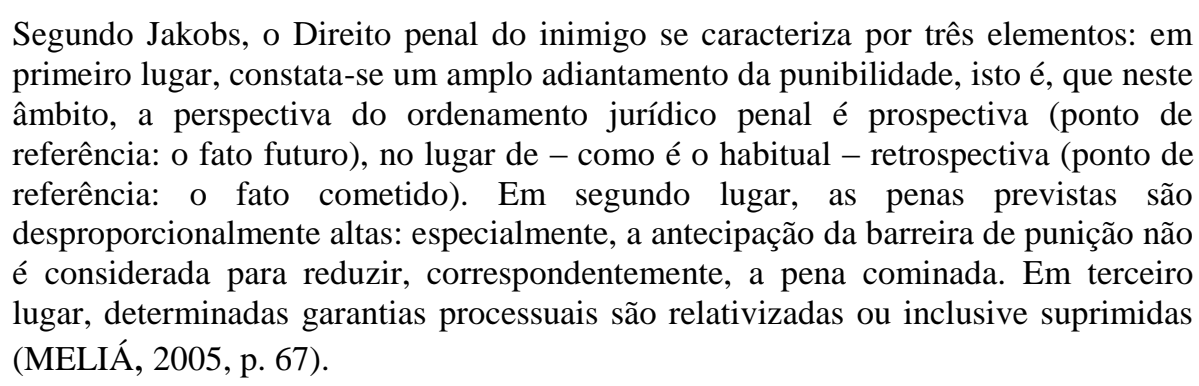

Deste modo, conclui-se que o Direito Penal do Inimigo, tal como o Funcionalismo Radical, tem como finalidade a manutenção da vigência da norma, porém somado com a distinção entre criminosos e a necessidade combater a classe chama de inimigos do Estado, mesmo que para isso seja necessária a supressão ou relativização de direitos e garantias legais atualmente ofertadas e protegidas pelo Estado Democrático de Direito.

\section{CONSIDERAÇÕES FINAIS}

Com base no que foi exposto no presente trabalho, há duas indagações que devem ser sugeridas e respondidas, as quais são: a) qual funcionalismo penal seria o mais adequado para uma possível aplicação? b) O Direito Penal do Inimigo é aceitável no Estado Democrático de Direito vigente no Brasil?

No que pese a primeira indagação, a delicadeza científica que as teorias do funcionalismo penal procuram, é a de explicar o questionamento: para que funciona o Direito Penal? 


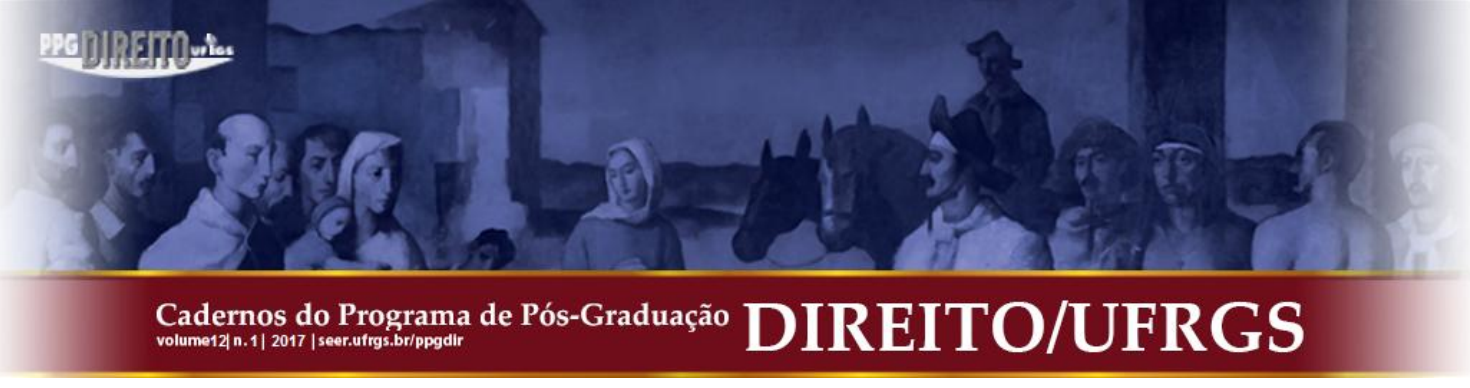

teoria funcionalista de Jakobs, já que pretende proteger a norma, não se importando com bens jurídicos, onde se revela intragável.

Ademais, Roxin da à importância devida para o princípio da insignificância, aplicando-o quando não afetado o bem jurídico, ao contrato de Jakobs, que o menospreza, tratando-se, assim, de uma concepção cuja preocupação não reflete a realidade que o sistema penal vive atualmente.

Posto isto, a teoria de Roxin apresenta-se como a mais adequada para aplicação, porém com devidas ressalvas, visto que suas ideologias apresentam-se um tanto ultrapassadas. Entretanto, tanto a humanização proposta, como os demais ensinamentos ofertados, engrandecem seus fundamentos e a colocam em visível ponto de aceitação, principalmente quando observado em lado oposto o funcionalismo de Jakobs.

$\mathrm{Na}$ seara da segunda indagação oferecida, observa-se, originado do pensamento funcionalista radical de Jakobs, o Direito Penal do Inimigo, o qual se verifica como a terceira velocidade do direito penal, pois busca a aplicação de penas rígidas, cumuladas com a relativização ou supressão de garantias penais e processuais penais, em detrimento aos chamados "inimigos do Estado", ou seja, para a classe de criminosos considerada de alta periculosidade.

Nesta teoria, defende Jakobs que o individuo desviado que pratica crime de alta periculosidade, infringindo a norma, deve ser considerado inimigo do estado, devendo ser tratado como tal, sofrendo, assim, suas sanções como forma de medida de segurança e coação estatal.

Mesmo sendo inegável a complexidade e qualidade de fundamentação do Direito penal do inimigo, pontua-se que sua aplicação não pode sequer ser sugerida no cenário atual, visto que representa uma ameaça, um ataque aos princípios e garantias do Estado de Direito. Tratar pessoas como inimigas, negando-as dignidade, suprimindo garantias legais e impedindo-as de reintegrar-se socialmente, como proposto nas medidas de seguranças de Jakobs, não aparenta ser a medida ideal e cabível para os entraves discutidos por Jakobs.

Sendo assim, apesar da crise humanística, o Estado Democrático de Direito roga por preservação de seus princípios, garantias e direitos, devendo qualquer ideologia maximalista ser combatida com a mesma força que se propõe. Não há inimigos, há cidadãos detentores de direitos e deveres, sujeitos a penas e sanções, porém, munidos de dignidade que deve ser preservada.

Cadernos do Programa de Pós-Graduação em Direito PPGDir./UFRgS | Edição Digital | Porto Alegre | Volume XII| Número 1 | 2017 | P. 379 - 398 


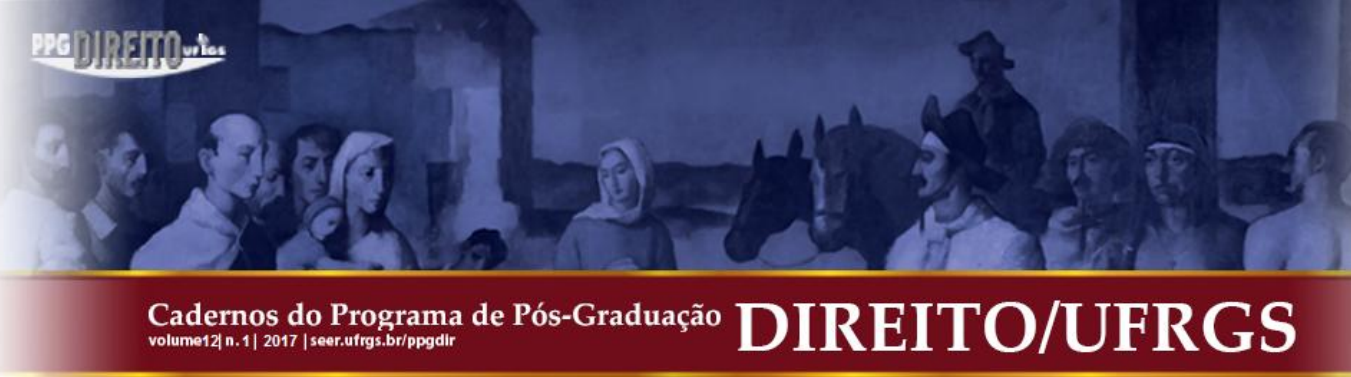

\section{REFERÊNCIAS}

BATISTA, Nilo. Novas Tendências do Direito Penal. Rio de Janeiro: Revan, 2004.

CALleGARI, André Luís et al. Direito Penal e Funcionalismo. Porto Alegre: Livraria do Advogado, 2005.

FERRI, Enrico. Princípios de Direito Criminal. 2. ed. Campinas: BookSeller, 1999.

FONSECA, Mariana Martins de Castilho. Uma Análise da Contribuição do Funcionalismo de Claus Roxin à Teoria da Ação. Revista Faculdade de Direito UFMG, Belo Horizonte, n. 54, p. 157-178, jan./jun. 2009.

GARCIA, Basileu. Instituições do Direito Penal. 4. ed. v. I. Tomo I. São Paulo: Max Limonad, 1976.

GOMES, Luiz Flávio. Direito Penal do inimigo (ou inimigos do Direito Penal). São Paulo: Notícias Forenses, 2004.

Direito penal: introdução e princípios fundamentais. 1. ed. v. 1. São Paulo: Editora Revista dos Tribunais, 2007.

GRECO, Luís. Introdução à dogmática funcionalista do delito. Em comemoração aos trinta anos de 'Política Criminal e Sistema Jurídico-Penal' de Roxin. Revista Brasileira de Ciências Criminais, v. 32, 2000.

HASSEMER, Winfried. Três temas de Direito Penal. Porto Alegre: Publicações Fundação Escola Superior do Ministério Público do Rio Grande do Sul, 1993.

Perspectivas del Derecho penal futuro.Revista Penal, Barcelona, n. 1, 1998.

JAKOBS, Günther. El concepto jurídico-penal de acción. Traducida por Manuel Cancio Melía. Madrid: Conferencia impartida em el CEU, 1992.

Sociedade, Norma e Pessoa: Teoria de Um Direito Funcional. v. 6. Tradução de Maurício Antonio Ribeiro Lopes. São Paulo: Manole, Coleção Estudos de Direito Penal, 2003.

JAKOBS, Günther; MELIÁ, Manuel Cancio. Direito Penal do Inimigo. In: OLIVEIRA, Eugenio Pacelli de; MOREIRA, Luiz (Orgs.). Rio de Janeiro: Lumen Juris, 2009.

- Direito Penal do Inimigo: Noções e Críticas. In: CALLEGARI, André Luis; GIACOMOLLI, Mereu José (Orgs.). 2. ed. Porto Alegre: Livraria do Advogado, 2005.

Direito Penal do Inimigo: Noções e Críticas. In: CALLEGARI, André Luis; GIACOMOLLI, Mereu José (Orgs.). 6. ed. Porto Alegre: Livraria do Advogado, 2012. 
. Manual de derecho penal del enemigo. Madrid: Editora Thosomcivitas, 2003.

JIMÉNEZ, Emiliano Borja. Algunos Planteamientos Dogmáticos em la Teoría Jurídica del delito en Alemania, Itália y Espana. Revista da Faculdade de Direito da Universidade Federal de Uberlândia, v. 34, 2006.

LARENZ, Karl. Metodologia de la ciencia del derecho. Traducida por E. Gimbernat Ordeig. Barcelona: Ariel, 1966.

MIR PUIG, Santiago Mir. Introducción a las bases del Derecho Penal. Barcelona: Bosch, 1976.

MORAES, Alexandre Rocha Almeida de. Direito Penal do Inimigo: A Terceira Velocidade do Direito Penal. Curitiba: Editora Juruá, 2011.

NIKITENKO, Viviani Gianine. Funcionalismo-Sistêmico Penal de Günther Jakobs: uma abordagem à luz do Direito Penal mínimo e garantista. Revista Direito em debate, n. 25, jan./jun. 2006.

PORTUGAL, Daniela. A Autopoiese no Direito e o Funcionalismo Sistêmico de Günther Jokobs na Aplicação da Lei Penal. Cadernos do Programa de Pós-Graduação em Direito PPGDir./UFRGS, v. 8, n. 2, 2013.

ROXIN, Claus. Funcionalismo e Imputação Objetiva no Direito Penal. Rio de Janeiro: Renovar, Tradução: Luís Greco, 2002.

Política Criminal e Sistema Jurídico-Penal. Rio de Janeiro: Renovar, 2000.

SILVA SÁNCHEZ, Jesús María. Aproximación al Derecho Penal Contemporáneo. Barcelona: JMB, 1992.

. A Expansão do Direito Penal. Aspectos da Política Criminal nas Sociedades PósIndustriais. Tradução de Luiz Otávio de Oliveira Rocha. São Paulo. Revista dos Tribunais, 2002.

La expansión del derecho penal: aspectos de la política criminal en las sociedades postindustriales. 2. ed., rev. e ampl. España: Civitas, 2001.

ZAFFARONI, Eugenio Raul; ALAGIA, Alejandro; SLOKAR, Alejandro. Derecho Penal: parte general. Buenos Aires: Ediar, 2001. 


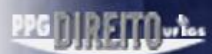

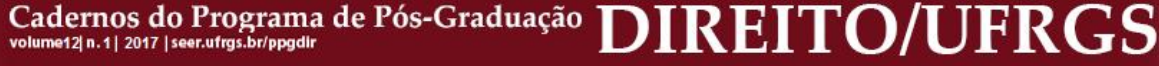

